\title{
Ultra-fast polymer optical fibre Bragg grating inscription for medical devices
}

\author{
Julien Bonefacino ${ }^{1}$, Hwa-Yaw Tam ${ }^{1}$, Tom S Glen ${ }^{1}$, Xin Cheng ${ }^{1}$, Chi-Fung Jeff Pun ${ }^{1}$, Jian Wang ${ }^{2}$, Po-Heng Lee ${ }^{2}$, \\ Ming-Leung Vincent $\mathrm{Tse}^{1}$ and Steven $\mathrm{T}$ Boles ${ }^{1}$
}

We report the extraordinary result of rapid fibre Bragg grating inscription in doped polymer optical fibres based on polymethyl methacrylate in only $7 \mathrm{~ms}$, which is two orders of magnitude faster than the inscription times previously reported. This was achieved using a new dopant material, diphenyl disulphide, which was found to enable a fast, positive refractive index change using a low ultraviolet dose. These changes were investigated and found to arise from photodissociation of the diphenyl disulphide molecule and subsequent molecular reorganization. We demonstrate that gratings inscribed in these fibres can exhibit at least a 15 times higher sensitivity than silica glass fibre, despite their quick inscription times. As a demonstration of the sensitivity, we selected a highly stringent situation, namely, the monitoring of a human heartbeat and respiratory functions. These findings could permit the inscription of fibre Bragg gratings during the fibre drawing process for mass production, allowing costeffective, single-use, in vivo sensors among other potential uses.

Light: Science \& Applications (2018) 7, 17161; doi:10.1038/lsa.2017.161; published online 23 March 2018

Keywords: bio-sensing; fibre Bragg grating; photosensitive dopant; polymer optical fibre

\section{INTRODUCTION}

Fibre Bragg gratings (FBGs) can be easily inscribed in silica optical fibres in $<1 \mathrm{~min}$, but the grating inscription time in polymethyl methacrylate (PMMA) optical fibres is much longer, and in some polymer optical fibres (POFs), this process takes $>1 \mathrm{~h}^{1,2}$. To date, the shortest reported inscription time using a $325 \mathrm{~nm} \mathrm{He}-\mathrm{Cd}$ laser is $1 \mathrm{~s}^{3,4}$, while a much faster grating inscription of $15 \mathrm{~ns}$ ( 1 pulse) was recently reported using an expensive high peak-power $248 \mathrm{~nm}$ excimer laser 5 . These times are too slow for the grating inscription to be carried out during the fibre-drawing process at a reasonable cost. Furthermore, PMMA starts to degrade upon irradiation with ultraviolet (UV) light below $\sim 300 \mathrm{~nm}^{6}$. Historically, PMMA was the preferred material for producing $\mathrm{POF}^{7-9}$ because of its ease of fabrication, low cost, high optical transparency in the visible region ${ }^{10}$ and refractive index similar to that of a conventional silica telecommunication optical fibre ${ }^{7,11}$ (1.457@643 nm for silica and $1.488 @ 632$ nm for PMMA). Here we demonstrate the fabrication of a single-mode POF using a unique core dopant, diphenyl disulphide (DPDS), which is responsible for both the increase in the core refractive index and the photosensitivity. We record the fabrication of FBGs that are UV-inscribed in $7 \mathrm{~ms}$, which is over 140 times faster than previous results reported for PMMA fibres $^{3,4}$, and we report the experimental results of a direct comparison of silica and polymer FBGs for monitoring vital signs.

Furthermore, we investigate the mechanism for this effect using Raman spectroscopy and chemical modelling.
POF sensors based on PMMA are a promising sensing technology, especially for the biomedical industry. PMMA fibres are biocompatible and immune from magnetic interference; they do not produce shards when they break, and they are inexpensive to produce ${ }^{12,13}$.

An interesting development currently being investigated is the use of a single conventional silica FBG sensor attached to the wrist to measure multiple vital signs of subjects ${ }^{14}$, including heart rate, blood pressure, body temperature, respiratory status and level of consciousness. The main issue in this application is that silica FBGs break easily and can produce sharp shards. To our knowledge, there are no reported results using POF-FBG for heartbeat measurements. The current state of the art shows that different techniques are employed $^{15-17}$, which require many pieces of expensive equipment. Another potential application of FBG sensors is in minimally invasive surgery. However, the Young's modulus of silica $\left(73 \mathrm{GPa}^{18}\right)$ is much higher than that of surgical tools made of super-elastic nitinol (41 $\mathrm{GPa}^{19}$ ), and small-diameter silica fibres must be used to reduce stiffness for better sensitivity ${ }^{20}$. PMMA typically has a much smaller Young's modulus $\left(\sim 4 \mathrm{GPa}^{21}\right)$, which makes it more suited for the aforementioned applications, and it is more sensitive than silica FBG for strain measurements. This work is a crucial step towards the development of a body-safe, sensitive, reliable and disposable fibre optics multi-vital-signs sensing system. Bio-sensing is one example application, but these results could also be of interest to the wider

${ }^{1}$ Photonics Research Centre, Department of Electrical Engineering, The Hong Kong Polytechnic University, Hung Hom, Kowloon, Hong Kong, China and ${ }^{2}$ Division of Urban Environment, Department of Civil and Environmental Engineering, The Hong Kong Polytechnic University, Hung Hom, Kowloon, Hong Kong, China Correspondence: J Bonefacino, Email: julien.bonefacino@gmail.com; HY Tam, Email: eehytam@polyu.edu.hk

Received 8 June 2017; revised 15 November 2017; accepted 16 November 2017; accepted article preview online 23 November 2017 The accepted article preview was available with the details: Light: Science \& Applications (2018) 7, e17161; doi: 10.1038/lsa.2017.161 
precision sensor industry and have potential in transportation, Internet of Things and automation applications.

\section{MATERIALS AND METHODS}

\section{Polymer optical fibre fabrication}

All of the fibres presented in this article were drawn from preforms that were fabricated using the 'pull-through' method with a core preform inserted in a cladding preform. This method, although similar, is different from the Teflon string method ${ }^{12,22,23}$, in which the core monomers are poured directly into a cladding preform. Details about preform fabrication using the 'pull-through' method are given in Supplementary Information. The fabricated fibres were $120 \mu \mathrm{m}$ in diameter, with a core of $5.5 \mu \mathrm{m}$.

\section{Fibre Bragg grating inscription}

A KIMMON He-Cd $325 \mathrm{~nm}$ laser (IK3501R-G) was used to fabricate the FBGs. Four mirrors were employed, which directed the beam through a 150-mm plano-convex cylindrical lens that focussed the beam onto the fibre. The fibre was secured on a Newport $125-\mu \mathrm{m}$ $\mathrm{V}$-groove using tape. Two layers of tape were adhered on each side of the V-groove, and a phase mask (Ibsen) was placed on top of the tape. The tape thickness is approximately $120 \mu \mathrm{m}$, which allows a small gap between the fibre and the phase mask; it prevents any particle transfer from the fibre to the phase mask. The pitch of the phase mask was $1046.3 \mathrm{~nm}$. Prior to FBG fabrication, the fibre was taped onto a hot plate for $1 \mathrm{~min}$ and was cut using a hot blade ${ }^{24}$.

A beam shutter (Thorlabs SH05) was placed in the optical path and controlled by a shutter controller (Thorlabs SC10), which allows a minimum irradiation time of $7 \mathrm{~ms}$. To expand the beam, a beam expander (Thorlabs BE10-UVB) was mounted between the third and fourth mirrors, forming a 12-mm-long elliptical beam on the $\mathrm{V}$-groove. All of the FBGs presented in this manuscript are strictly $10 \mathrm{~mm}$ long, delimited by tape. The optical power of the UV beam measured after the lens was $\sim 25.5 \mathrm{~mW}$ (using Thorlabs S120VC). The same optical output power was used to inscribe all of the FBGs presented in this work. This inscription method offers two main advantages: (1) it shortens the FBG inscription time, and (2) it can irradiate the whole phase mask at once. This irradiation scheme required only low power density $\left(1.53 \mathrm{~mJ} \mathrm{~cm}{ }^{-2}\right)$ and was sufficient for writing good-quality FBGs in just $7 \mathrm{~ms}$. All of the fibres used in the manuscript were annealed at $80^{\circ} \mathrm{C}$ for 2 days prior to grating inscription to remove the stress induced during the drawing process. Details concerning the FBG fabrication process and interrogation of the sensor are given in Supplementary Information.

\section{Filtering protocol to extract the heartbeat and respiration signals} To extract meaningful heartbeat and respiration signals, a Labview program was used to filter the raw data collected by the FBG sensor. An adjustable bandpass filter was applied to remove noise signals. For the respiration measurement, low- and high-cut frequencies of 0.15 and $0.3 \mathrm{~Hz}$ were applied, respectively; for the heartbeat measurement, 2 and $8 \mathrm{~Hz}$ were applied, respectively. Automatic counting of peakand-trough of the resultant signal was performed by setting different thresholds of the wavelength shift for different subjects.

\section{Raman spectroscopy}

Fabricated POF and preforms were cut into $\sim 2 \mathrm{~cm}$ lengths and were taped together using Kapton tape and held vertically inside a cylindrical mould. The mould was filled using Buehler's EpoKwick ${ }^{\circledR}$ epoxy resin and left to set overnight. The embedded fibres were removed from the mould and cut into three sections. These sections were ground and polished. Silicon carbide waterproof paper of 150 grit was used to remove the rough edges from the cutting and to ensure that the sections were of equal height. They were then attached to a plate for automatic milling. Sequential grits of up to 2000 were used on an EQ-Unipol-802 machine to obtain a smooth top surface. This step was followed by alumina slurry and polishing pads, with particle sizes of 3, 0.3 and 0.05 microns sequentially, giving a mirror finish. The sections were rinsed with deionized water before sonication in deionized water for $15 \mathrm{~min}$ to ensure a clean surface. Once dry, POFs could be imaged using a Leica DM4000 optical microscope to ensure that the core region was visible.

Raman spectra of the POF cross-sections were taken using a Horiba LabRAM HR 800 spectrometer, with a $633 \mathrm{~nm}$ laser. Spectra with good signal-to-noise ratios were acquired between Raman shifts of 200 and $3500 \mathrm{~cm}^{-1}$ using a dwell time of $6 \mathrm{~s}$, averaged 3 times, with subpixel averaging of 4 . Faster Raman spectra were also acquired using a dwell time of $3 \mathrm{~s}$, zero averaging and no subpixel averaging. Such spectra were then taken at several different locations and averaged, producing very similar graphs to the longer dwell time acquisitions. This procedure was performed to ensure that there was no spatial variation across the sample.

\section{Chemical modelling}

Chemical modelling was accomplished by performing $a b$ initio electronic structure calculations using the Gaussian 09 program package $^{25}$. Structural optimizations were obtained using the B3LYP hybrid density functional with a $6-311++G(d, p)$ basis set. Frequency calculations at the same level were performed to investigate whether the obtained stationary point is an isomer. The reported relative Gibbs free energy $(\Delta G)$ and enthalpy $(\Delta H)$ are calculated at $298 \mathrm{~K}$, and the relative electronic energy $(\Delta E)$ is corrected by including a zero-point energy (ZPE).

\section{RESULTS AND DISCUSSION}

\section{Fibre characteristics}

Typically, the photosensitivity and refractive index of the core of a POF are increased by using two different materials. For example, dopants such as trans-4-stilbenemethanol were used to enhance the photosensitivity and benzyl methacrylate $e^{12,26}$ or diphenyl sulphide ${ }^{3}$ to increase the refractive index. In some POFs, benzyl methacrylate was replaced by diphenyl sulphide because of the lower transmission loss. Here a single active chemical compound, DPDS, was used to provide for both the ultra-photosensitivity and the increase of the refractive index in the fibre core, albeit with a slightly higher loss compared with pure PMMA, without consequence for the intended application. Preforms were fabricated using the 'pull-through' technique described in Materials and Methods and further detailed in Supplementary Information, which allows control of the refractive index profile, an essential condition for the fabrication of a single-mode fibre. The cladding was made of pure PMMA, and the core consisted of $\mathrm{PMMA}_{92 \% \mathrm{wt}}+\mathrm{DPDS}_{8 \% \mathrm{wt}}$. Note that the dopant is sometimes referred to in \%mol of MMA monomer. In the present case, the core dopant concentration was $4 \% \mathrm{~mol}$.

The average transmission loss of the DPDS POF was measured by the multiple cutback method. The fibre was cut by hand using a hot plate and razor blade ${ }^{24}$. A SLED source (EXALOS EXS210018-01) and a fibre optic power meter (Thorlabs PM320E) with an integrating cavity detector head (Thorlabs S142C) were used for the measurements. The fibre has loss values of $87.12 \mathrm{~dB} \mathrm{~m}^{-1}$ at $1550 \mathrm{~nm}$ and $26.67 \mathrm{~dB} \mathrm{~m}^{-1}$ at $870 \mathrm{~nm}$ for a concentration of $8 \% \mathrm{wt}(4 \% \mathrm{~mol})$ of DPDS in the fibre core. The high attenuation value is mainly 


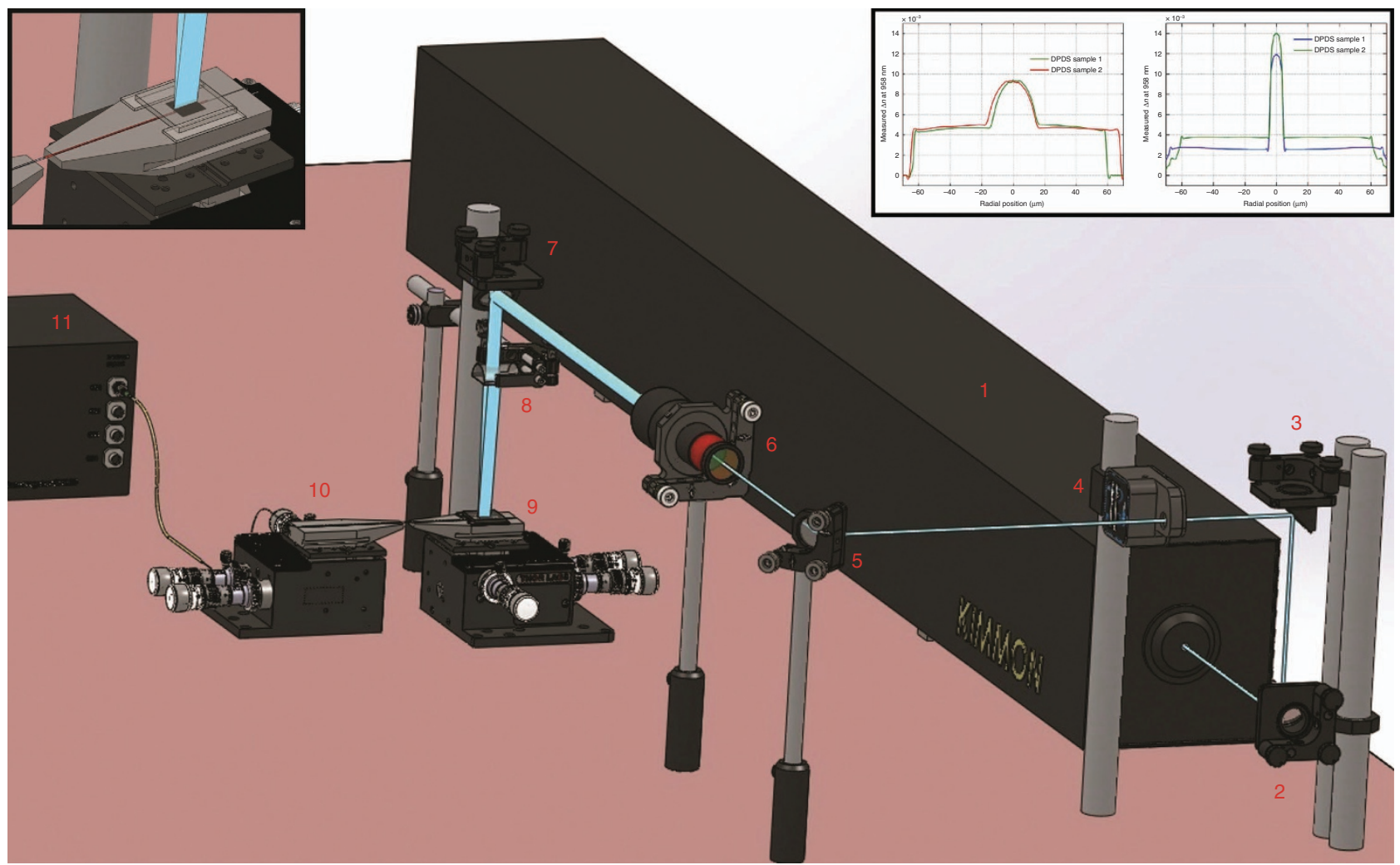

Figure 1 Polymer optical FBG fabrication setup using a static beam. The setup used 4 mirrors $(2,3,5$ and 7$)$ to guide the laser beam from (1) to (9). The beam shutter (4) is inserted in the optical path after the second mirror (3), and the $10 \times$ beam expander (6) was placed after the third mirror (5) to expand the beam. The plano-convex cylindrical lens (8) focuses the beam onto the fibre. The FBGs' spectra was recorded with an FBG interrogator (11) via an angled-cleaved single mode fibre (10). The upper left corner shows the POF with the phase mask placed on top of the V-groove. The measured refractive index profiles at $958 \mathrm{~nm}$ of two samples of DPDS core-doped POFs fabricated using the Teflon string method (left) and DPDS core-doped fibres fabricated using the 'pull-through' method (right) are shown in the upper right corner.

attributed to the current laboratory conditions and the simple chemical purification process and can be significantly reduced by fabricating the preform in an enclosed environment ${ }^{27}$. The attenuations of commercial PMMA fibres at the wavelengths of 870 and $650 \mathrm{~nm}$ are $\sim 5$ and $\sim 0.5 \mathrm{~dB} \mathrm{~m}^{-1} 10$, respectively. We measured the additional loss induced by DPDS at $0 \%$ wt, $2 \%$ wt (1\%mol), $4 \%$ wt (2\% $\mathrm{mol}$ ) and $8 \% \mathrm{wt}(4 \% \mathrm{~mol})$ (described in Supplementary Information), and we obtained 0.98 and $1.75 \mathrm{~dB} \mathrm{~m}^{-1} \% \mathrm{wt}^{-1}$ at 650 and $870 \mathrm{~nm}$, respectively. This finding indicates that DPDS-doped PMMA-POF with a loss of $\sim 2.5 \mathrm{~dB} \mathrm{~m}^{-1}$ at $650 \mathrm{~nm}$ can be fabricated, which permits sensor interrogation of over $2 \mathrm{~m}$ with a round-trip loss of approximately $10 \mathrm{~dB}$.

\section{Fibre Bragg grating inscription set-up}

The optical set-up for the millisecond grating inscription is depicted in Figure 1. The single-core dopant is sufficient to increase the refractive index and to substantially enhance the photosensitivity to permit the inscription of FBGs in milliseconds. Moreover, the POF operates in the single-mode regime with a good refractive index profile (see inset of Figure 1).

The refractive index profiles of POFs that were fabricated using two different methods were measured with a fibre index profiler (IFA$-100^{\mathrm{TM}}$ from Interfiber Analysis $\left.{ }^{\circledR}\right)$ in Sharon, MA, USA. Examples of the measurements for two fibres with a larger core are shown in the left-hand side in the inset of Figure 1. The profiles for fibres fabricated using the Teflon string method ${ }^{12}$ (left) show significant dopant diffusion from core to cladding. The diffusion occurred during the core polymerization process, which makes it difficult to produce single-mode fibres. The results for fibres fabricated using the 'pullthrough' technique show virtually no dopant diffusion (right); the measured profiles show an excellent abrupt change in the refractive index between the core and the cladding.

\section{Fabrication of ultrafast FBGs}

The novel core dopant and irradiation scheme required only low power density $\left(1.53 \mathrm{~mJ} \mathrm{~cm}^{-2}\right)$ and was deemed to be sufficient for writing FBG in just $7 \mathrm{~ms}$. Figure $2 \mathrm{a}-2 \mathrm{c}$ shows the spectra recorded $10 \mathrm{~s}, 1 \mathrm{~h}$ and 14 days after UV irradiation for FBGs written in $10 \mathrm{~s}$, $0.3 \mathrm{~s}, 0.2 \mathrm{~s}$ and $7 \mathrm{~ms}$. Note that all of the FBGs appeared almost immediately after the UV irradiation. The most important result is the formation of the millisecond FBGs. As shown in Figure 2a, 7 ms FBGs exhibited signal-to-noise ratios of $7 \mathrm{~dB}, 10 \mathrm{~s}$ after UV irradiation. Figure $2 \mathrm{~b}$ and $2 \mathrm{c}$, shows that all of the FBGs experienced significant post-irradiation growth. At 14 days after UV irradiation, the signal-tonoise ratio of the $7 \mathrm{~ms}$ FBGs increased to $14.8 \mathrm{~dB}$.

The FBGs written with $0.3 \mathrm{~s}$ or longer UV irradiation time exhibited a higher noise level and larger full-width-half-maximum than FBGs inscribed in a shorter time. The full-width-half-maximum of FBGs inscribed in less than $0.3 \mathrm{~s}$ was measured to be $80 \mathrm{pm}$, 14 days after the inscription. Millisecond FBGs exhibited suppressed side lobes with a high signal-to-noise ratio, which is desirable for sensing applications. These breakthrough results demonstrate the feasibility of writing FBGs in POFs during the fibre-drawing process. 
a FBGs spectra recorded $10 \mathrm{~s}$ after inscription

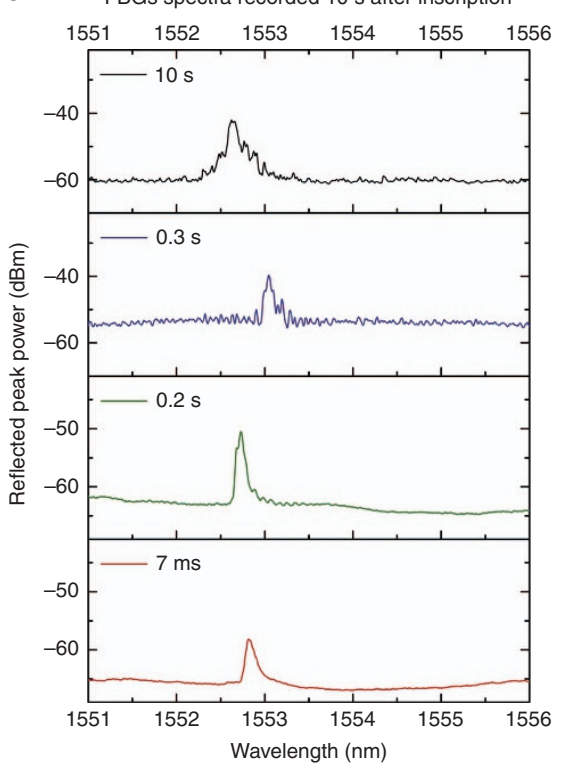

b

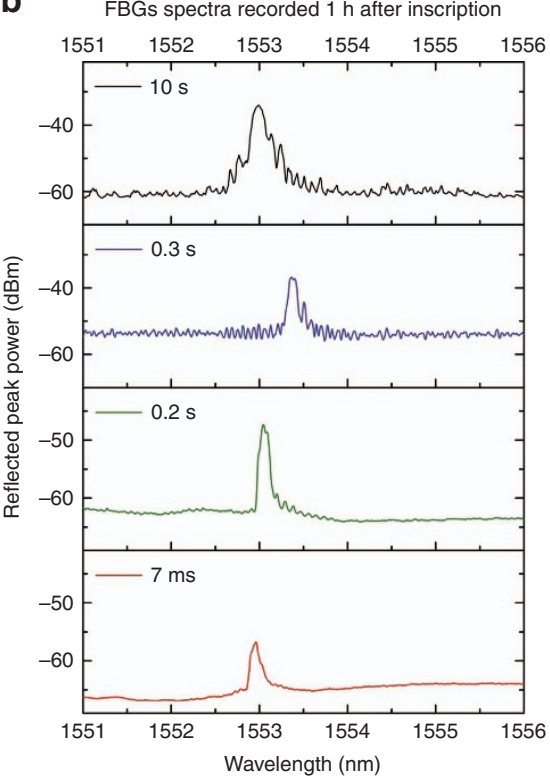
$\begin{array}{llllll}1551,1552 & 1553,1554,1555,1556\end{array}$

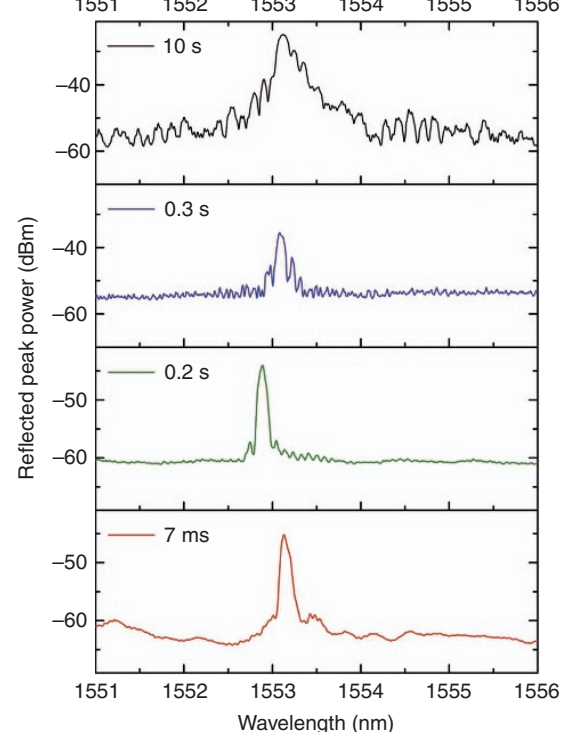

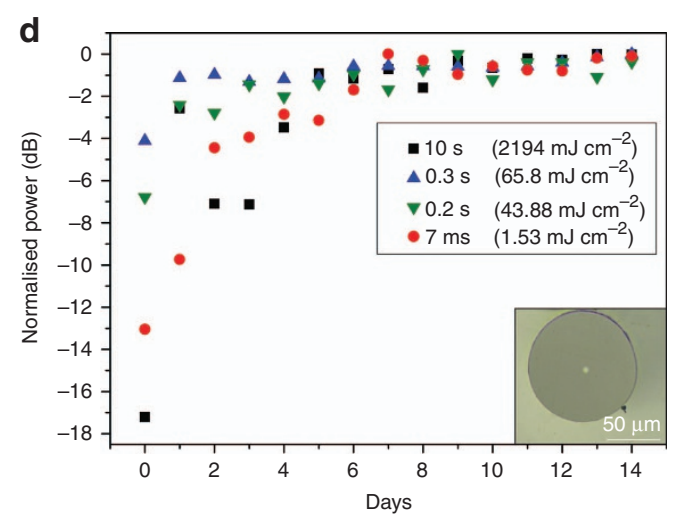

Figure 2 Measured reflection spectra of FBGs inscribed with different UV irradiation times in the POF and their growth post-irradiation. (a) Gratings recorded $10 \mathrm{~s}$ after inscription, (b) $1 \mathrm{~h}$ after inscription and (c) 2 weeks after inscription. (d) Growth of the normalized reflected peak power of FBGs written in $10 \mathrm{~s}$, $0.3 \mathrm{~s}, 0.2 \mathrm{~s}$ and $7 \mathrm{~ms}$ within 2 weeks post-irradiation. The inset shows the end face of the fabricated single-mode POF.

\section{Stability of the gratings}

Gratings written in polymer fibres can be unstable ${ }^{28}$, and their peak wavelength and power can fluctuate with time. One reason for the instability is the stress induced in the POFs during the fibre-drawing process $^{29}$. In practice, the stress is slowly released by thermal annealing at $\sim 80^{\circ} \mathrm{C}$ for many hours ${ }^{30}$. Figure $2 \mathrm{~d}$ shows the normalized reflected peak power fluctuations for gratings left in an air-conditioned laboratory without strict control of the temperature or humidity for up to 2 weeks post-irradiation. Significant fluctuations in the peak power were observed during the first few days after inscription. All of the FBGs stabilized after approximately a week, and the growth of the reflected peak power in milliseconds FBGs is more pronounced for the 7 -ms grating. It is apparent from Figure $2 a-2 c$ that there is a common growth regime for gratings written with UV fluence below $\sim 65 \mathrm{~mJ} \mathrm{~cm}^{-2}(0.3 \mathrm{~s})$ because the peak stabilized at the same level. In general, the reflected peak power is proportional to the UV fluence up to a certain threshold, at which degradation occurs ${ }^{31}$. Interestingly, the growth of the 7-ms grating continued for months at a very slow pace, as demonstrated in the next section. The dependence of the refractive index modulation and the UV dose is detailed in
Supplementary Information. The inset in Figure $2 \mathrm{~d}$ shows the end face of the fabricated single-mode fibre.

To characterize the stability of the FBGs for biomedical applications, thermal tests were conducted using an environmental chamber (ESPEC, SH-641) with the humidity set at 30\%. The FBGs were placed inside the chamber with a temperature profile program for $8 \mathrm{~h}$, in the range of $20-50^{\circ} \mathrm{C}$. Ten cycles of the program were executed. Figure $3 \mathrm{a}-3 \mathrm{c}$ shows the results of the stabilized FBGs inscribed in $10 \mathrm{~s}$, $0.3 \mathrm{~s}$ and $7 \mathrm{~ms}$, respectively.

The Bragg peak shifts to a shorter wavelength with a higher temperature, which is consistent with previous findings ${ }^{30,32,33}$. The initial shift for all of the FBGs within the first $2 \mathrm{~h}$ was due to a decrease in the humidity from that of ambient air to $30 \%$, while the temperature was stabilized at $20^{\circ} \mathrm{C}$. Interestingly, all of the FBGs exhibit clear stability. Furthermore, the FBGs exhibited a good thermal response, and their average sensitivities during the last three cycles were approximately $-55 \mathrm{pm}^{\circ} \mathrm{C}^{-1}$ for the $0.3 \mathrm{~s}$ FBGs and around $-40 \mathrm{pm}^{\circ} \mathrm{C}^{-1}$ for the $10 \mathrm{~s}$ and $7 \mathrm{~ms}$ FBGs. The difference in the sensitivity or temperature coefficient is mainly due to the unintended inhomogeneity of the fibre. Figure $3 \mathrm{~d}$ shows the results of 10 humidity 

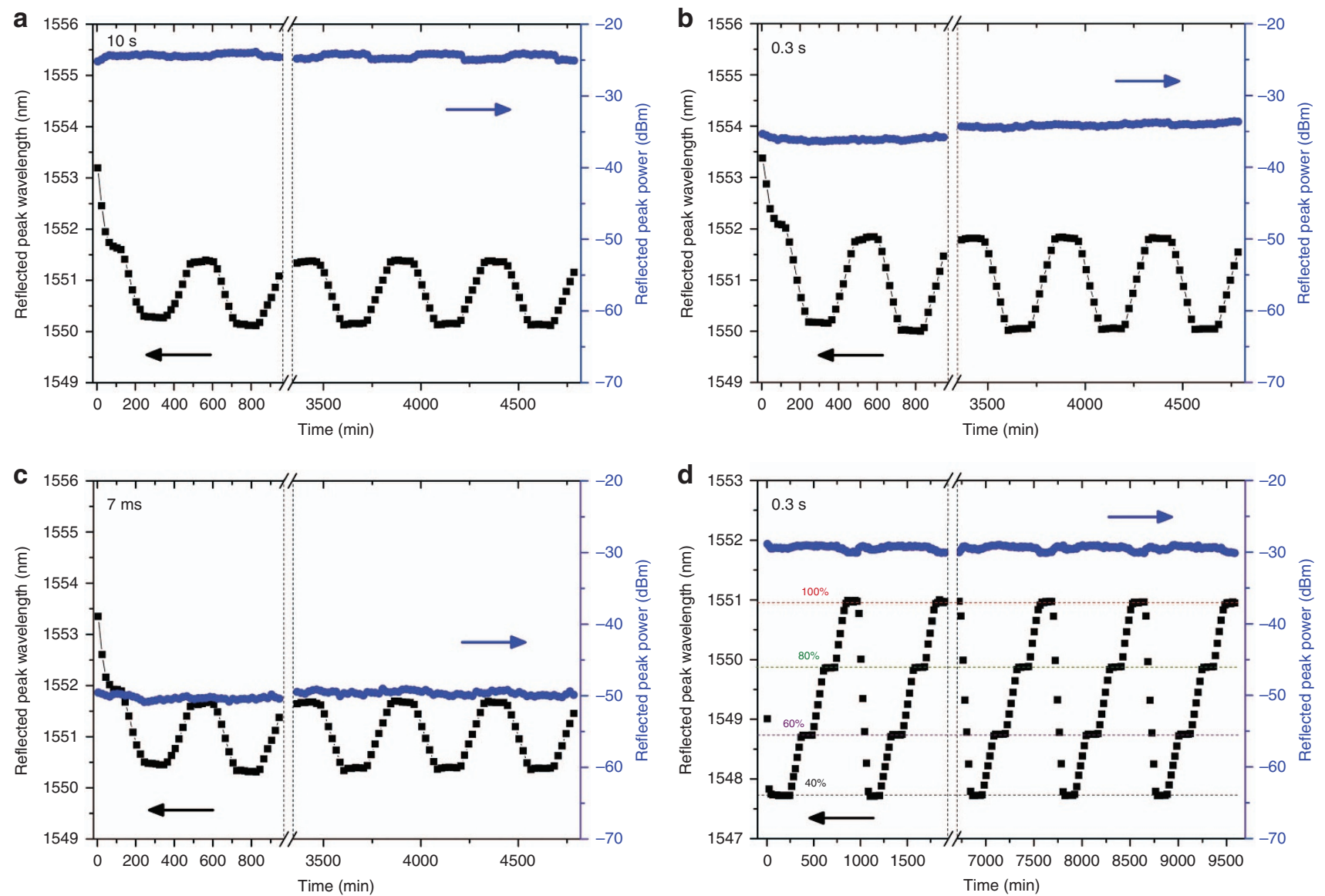

Figure 3 Wavelength and peak power fluctuations during temperature and humidity cycling. The temperature profile was set between 20 and $50{ }^{\circ} \mathrm{C}$. Each cycle consists of $2 \mathrm{~h}$ for stabilization at 20 and $50{ }^{\circ} \mathrm{C}$ and $2 \mathrm{~h}$ for the increase and decrease between the two temperatures, which totalled $8 \mathrm{~h}$. The results of 10 cycles are recorded for (a) $10 \mathrm{~s} \mathrm{FBG,} \mathrm{(b)} 0.2 \mathrm{~s} \mathrm{FBG}$ and (c) 7 ms FBG. The results for 10 humidity cycles between $40 \% \mathrm{RH}$ and $100 \% \mathrm{RH}$ at a constant temperature of $40^{\circ} \mathrm{C}$ are shown in d. Each cycle consists of $2 \mathrm{~h}$ for stabilization at each humidity level and $2 \mathrm{~h}$ for the increase and decrease between the stated levels. For all of the graphs, only the first two and last three cycles are plotted, with the dash line representing the missing cycles.

cycles performed at a temperature of $40^{\circ} \mathrm{C}$. The test protocol was similar to the protocol used for temperature cycling. Remarkable peak power stability is demonstrated, and a sensitivity of $54.2 \mathrm{pm} \%$ $\mathrm{RH}^{-1} \pm 0.14 \% \mathrm{RH}$ was recorded. These test results demonstrated the excellent thermal and humidity stability of the fabricated FBGs, qualifying it for biomedical applications and potentially for in vivo sensing.

\section{Multiple vital signs monitoring using FBG sensors}

Silica glass and polymer FBG sensor heads were attached to the subject's brachial artery location using medical tape (Supplementary Fig. S4). The system consisted of an interrogator (Micron Optics, SM130) with a sampling rate set at $1 \mathrm{kHz}$, which permitted collection of the peak wavelength shift. As the POF-FBG reflected signal was low, an optical gain of $20 \mathrm{~dB}$ was set on the Micron Optics software, allowing easier automatic peak detection. The data were recorded using a Labview program, and each test lasted for $1 \mathrm{~min}$. The heartbeat measurements were compared with a medical device (Nellcor, N20PA handled pulse oximeter) based on photophlethysmography, with an accuracy of $\pm 3 \mathrm{bpm}$. The medical device is composed of an infrared light source and a detector. The heartbeat is responsible for a change in the blood volume of the finger. As the light is partially absorbed by the blood, recording the reflected light gives the value of the heartbeat.
Heartbeat measurements at the brachial artery location

The reflection spectrum for a typical silica FBG is shown in Figure 4a, and the reflection spectrum of a 7-ms POF grating that was used in the experiment is shown in Figure $4 \mathrm{~b}$. The POF-FBG used was manufactured 10 months earlier and exhibited reflected peak power growth within this time. A demonstration was conducted for monitoring the pulse rate using the two FBG sensors.

A comparison of the experimental results obtained with FBGs inscribed in the two materials shows that the polymer sensor has a much larger wavelength shift (approximately $15 \mathrm{pm}$ ) than that of the silica sensor (approximately $0.8 \mathrm{pm}$ ), as shown in Figure 4c. This finding suggests that there is a sensitivity improvement of approximately 20 times by using a polymer FBG instead of a conventional silica $\mathrm{FBG}^{14}$. Experimental results obtained with the POF-FBG match those measured using a medical device, which demonstrates the quality and accuracy of the measurements. The reliability of the POF bio-sensor was further investigated and is presented in Supplementary Fig. S5 in Supplementary Information. The filtered pulse shape acquired by the POF grating ${ }^{34}$ can be used to estimate the blood pressure, as demonstrated by Katsuragawa and Ishizawa ${ }^{14}$. It is important to note that the measured wavelength shift of $<2 \mathrm{pm}$ obtained with the silica FBG sensor is similar to that reported by Katsuragawa and Ishizawa ${ }^{14}$, who used a much higher-resolution FBG interrogator. 

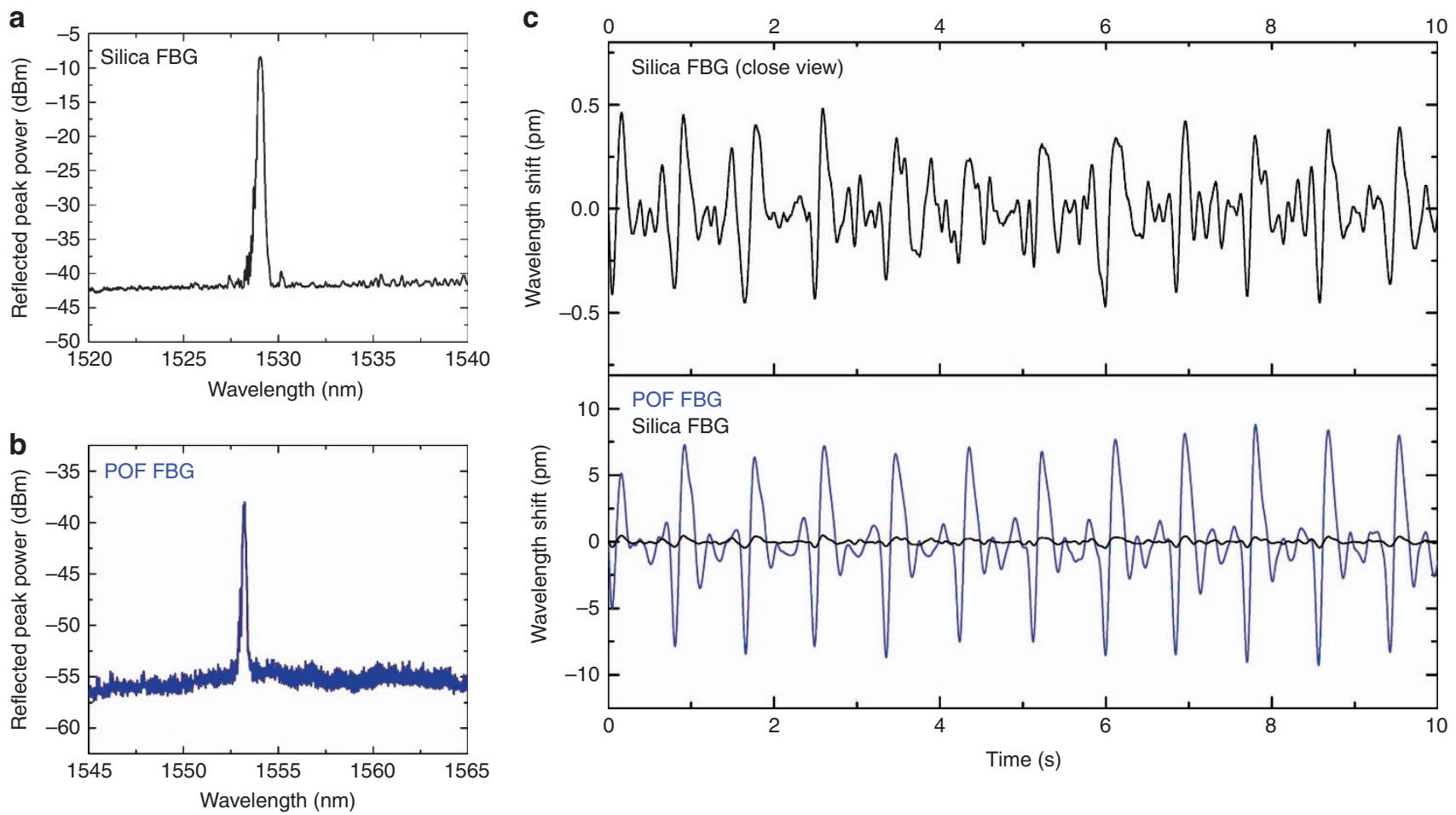

Figure 4 FBG waveforms generated from heartbeat monitoring. (a) Reflection spectrum of the silica FBG used in the experiment. (b) Reflection spectrum of the 7 ms polymer FBG (stabilized for a few months after UV exposure) used in the experiment. (c) Filtered reflection peak wavelength shift of the silica (top) and polymer FBG (bottom).

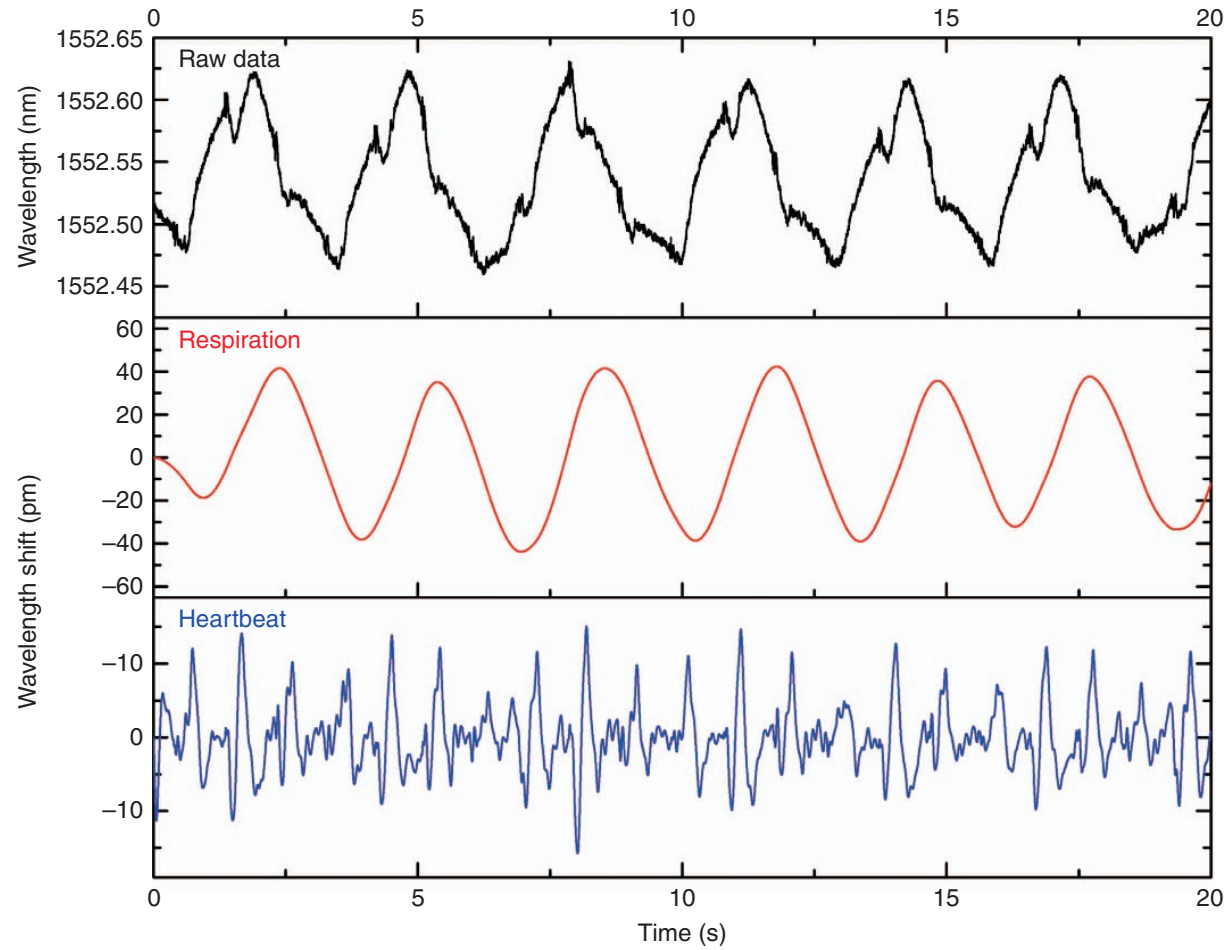

Figure 5 Waveforms for simultaneous respiration and heartbeat monitoring. (Top) Raw data for the reflection wavelength peaks. Waveforms generated after filtering the raw data to monitor the (middle) respiration and (bottom) heartbeat. 

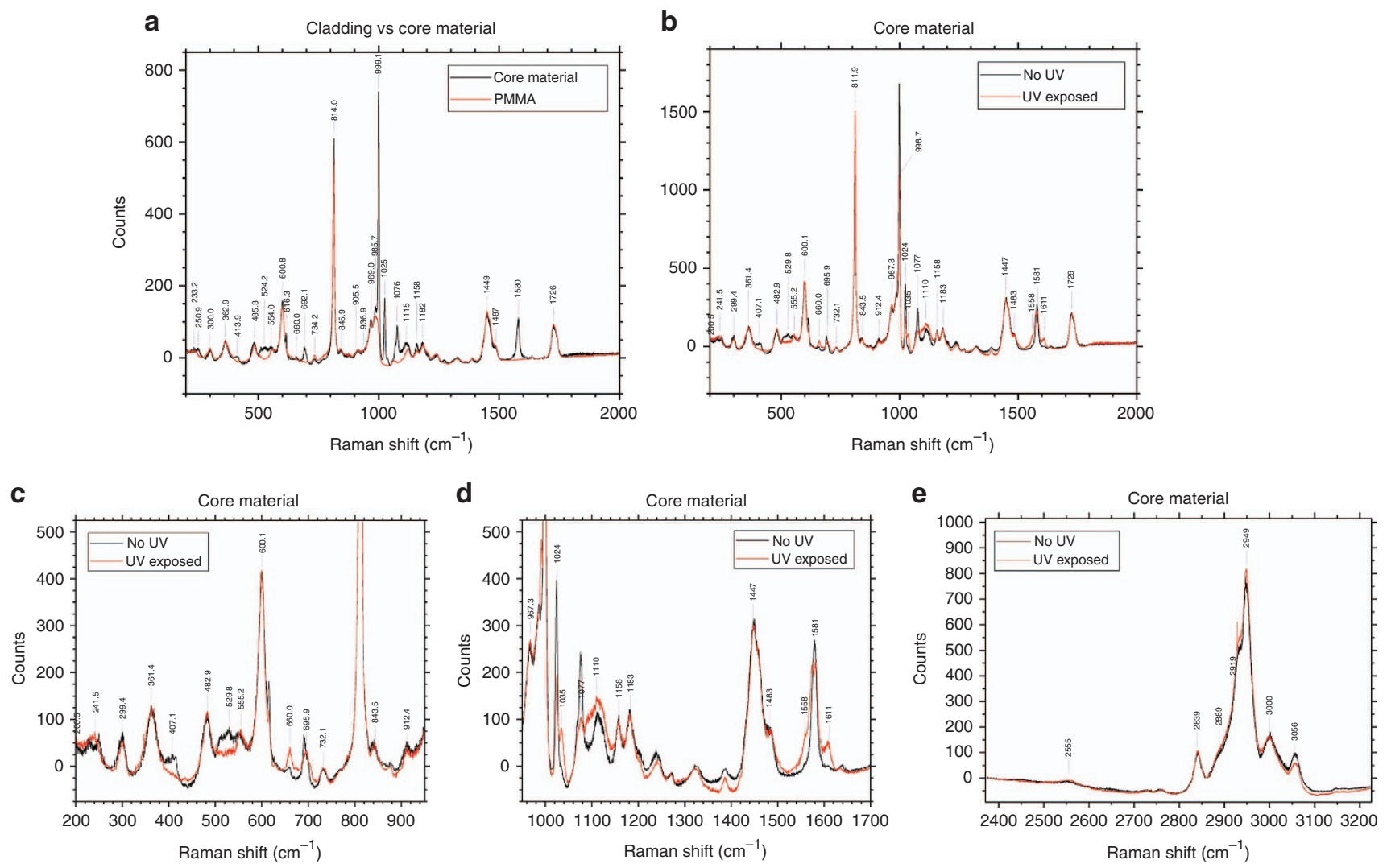

Figure 6 Raman spectroscopy of fibre materials. Panel (a) shows the comparison between the core and the cladding materials, while panel (b) shows the effect of UV exposure on the core. Closer views of $\mathbf{b}$ are shown in $\mathbf{c}$ and $\mathbf{d}$, while e shows the longer Raman shift part of the spectrum.

\section{Heartbeat and respiration record on chest}

Another study was conducted for multiple human vital sign monitoring using the $7 \mathrm{~ms}$ polymer FBG. For this demonstration, a single FBG was attached to the subject's chest. Figure 5 shows the raw data for the detection of the reflection peak wavelengths; the extracted waveforms generated from respiration and heartbeats are separately shown in the figure. The wavelength shift obtained for the filtered respiration signal is approximately $80 \mathrm{pm}$, whereas it was approximately $17 \mathrm{pm}$ for the filtered heartbeat signal. These results are more accurate and reliable than other results using POF macro-bending sensors ${ }^{15,16}$ and optical time-domain reflectometer-based sensors ${ }^{17}$ without requiring special preparation nor expensive equipment. Further experiments were conducted together with a comparison with silica FBG, and the findings are presented in Supplementary Information (Supplementary Fig. S6a-S6d). It is demonstrated that POF-FBG exhibit wavelength shifts that are at least 30 times larger than those of silica FBG for both respiratory function and heartbeat monitoring. Note that silica FBG embedded in textiles demonstrated a sensitivity of $150 \mathrm{pm}$ for respiration monitoring and approximately $8 \mathrm{pm}$ for cardiac activity ${ }^{35}$ - However, the FBG was embedded in a polyvinyl chloride foil substrate that enabled a large sensitive area, permitting higher sensitivity.

\section{UV-induced changes in PMMA and DPDS}

Raman spectroscopy was conducted on embedded POFs and core preforms to study the molecular changes caused by the FBG writing process. The signal from the core of a fibre was mainly dominated by the PMMA, and thus the core material preforms were investigated to study the effect of UV on the PMMA-DPDS mixture. Figure 6a shows the Raman spectra obtained when the core materials were tested and compared with the cladding. Peak identification was conducted using Raman spectra found in the literature for DPDS, similar phenyl-based molecules and PMMA ${ }^{36-39}$. These spectra are very similar, unsurprisingly, because the core is mainly the same material as the cladding, with the differences arising from the DPDS.

The first difference between the spectra is a small peak at $250.9 \mathrm{~cm}^{-1}$, which is attributed to the bending vibration of a C-S-S group $(\delta(C-S-S))$. A second clear difference is seen at $413.9 \mathrm{~cm}^{-1}$, a frequency that has contributions from both a phenyl mode $\left(\phi_{7 \mathrm{a}}\right)$ and a stretching S-S $(v(S-S))$ bond. The next difference is seen at $524.2 \mathrm{~cm}^{-1}$, which is attributed to $\mathrm{v}(\mathrm{S}-\mathrm{S})$. The sharp peak at $616.3 \mathrm{~cm}^{-1}$, attributed to a phenyl mode $\left(\phi_{6 \mathrm{~b}}\right)$, is not seen in the cladding spectra. A small peak is observed in the core spectra at $660.0 \mathrm{~cm}^{-1}$ (Figure 6a), which is attributed to the C-S bond. The peak at $692.1 \mathrm{~cm}^{-1}$ has contributions from both a phenyl mode $\left(\phi_{6 \mathrm{~b}}\right)$ and the stretching of the C-S-S bond ( $(\mathrm{C}-\mathrm{S}-\mathrm{S}))$. These differences in the peaks are caused by phenyl, C-S-S, C-S or S-S vibrations, which confirms the successful detection of DPDS in the core material of the fibre.

Large differences seen at 999.1, 1025, 1076 and $1580 \mathrm{~cm}^{-1}$ are all attributed to various phenyl vibrations, although the $999.1 \mathrm{~cm}^{-1}$ has contributions from the $\mathrm{O}-\mathrm{CH}_{3}$ rock, and the $1076 \mathrm{~cm}^{-1}$ also has a contribution from $v(\mathrm{C}-\mathrm{S}-\mathrm{S})$ vibrations. Owing to its many vibrational modes and resonances, the phenyl signal is stronger than the contribution from the sulphur-related bonds.

Comparison between spectra taken from the core before and after the fibre is exposed to UV, shown in Figure 6b, reveals changes to the 


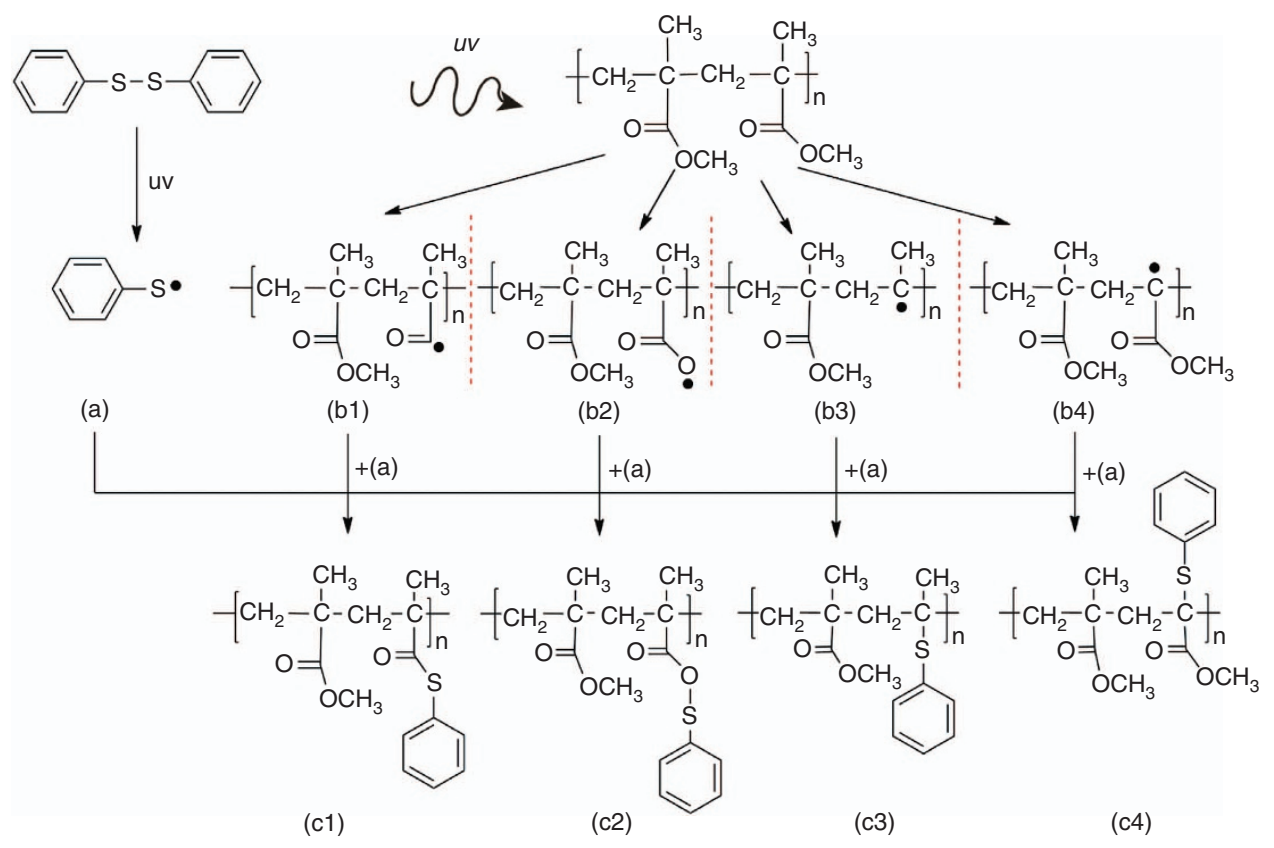

Figure 7 Chemical reactions considered in the energy calculations. Upon UV exposure, we assume that DPDS is cleaved into two sulphenyl radicals (a) while the PMMA chain (here modelled by only two monomers linked together) undergoes various photodegradation reactions, four possibilities of which are considered here (b1-b4). These are the removal of the $\mathrm{OCH}_{3}$ group from the side chain (b1), removal of the $\mathrm{CH}_{3}$ group on the side chain (b2), complete removal of the side chain (b3) and removal of the $\mathrm{CH}_{3}$ group opposite the side chain (b4).

bonding of these molecules. These are shown in Figure $6 \mathrm{~b}$, with closer views in Figure $6 \mathrm{c}$ and $6 \mathrm{~d}$.

After UV exposure, the peak at $250.9 \mathrm{~cm}^{-1}$ has shifted to a lower wavenumber and merged with the peak at $233.2 \mathrm{~cm}^{-1}$. The next change is seen at $407.1 \mathrm{~cm}^{-1}$, with the $\phi_{7 \mathrm{a}} / \mathrm{v}(\mathrm{S}-\mathrm{S})$ peak no longer present. There is also a decrease in the intensity of the $\mathrm{v}(\mathrm{S}-\mathrm{S})$ peak at $529.8 \mathrm{~cm}^{-1}$. A small increase in the peak at $660.0 \mathrm{~cm}^{-1}$ is seen, while a small decrease in the adjacent peak at $695.9 \mathrm{~cm}^{-1}$ is attributed to a combination of $\phi_{6 \mathrm{~b}}$ and $\mathrm{v}(\mathrm{C}-\mathrm{S}-\mathrm{S})$. The phenyl signal is seen to decrease, sometimes significantly, at $616,998.7,1024$ and $1077 \mathrm{~cm}^{-1}$. A peak at $1035 \mathrm{~cm}^{-1}$ is seen to increase. Peaks that split or develop shoulders are also of interest. The $998.7 \mathrm{~cm}^{-1}$ peak, associated with $\phi_{12}$ and the $\mathrm{O}-\mathrm{CH}_{3}$ rock, decreases after UV exposure, while a small shoulder develops at $991.3 \mathrm{~cm}^{-1}$. A similar change is seen at the $1580 \mathrm{~cm}^{-1}$ peak $\left(\phi_{8 \mathrm{a}}\right)$, with a splitting into two peaks that are very close in wavenumber. Two further shoulders have also developed at 1558 and $1611 \mathrm{~cm}^{-1}$. This shows a significant change to the phenyl ring $\phi_{8 \mathrm{a}}$ vibrations after UV exposure. Some small changes in the bonds that involve hydrogen are shown in Figure 6e, although it should be noted that the $-\mathrm{S}-\mathrm{H}$ bond vibration at $2555 \mathrm{~cm}^{-1}$ is not seen to change.

These results can be mainly split between changes in the carbonsulphur bonding and changes to the phenyl rings. Both can provide information about what occurs inside a fibre after UV light exposure and will be discussed further in the next sections.

\section{Chemical modelling of a fibre system}

Electronic structure calculations were used to further investigate the effect of UV exposure on the POFs. The simulation parameters are given in the Materials and Methods section. Various possible reaction pathways were considered to determine which was the most thermodynamically favourable. These are outlined in Figure 7.

It was assumed that the UV light causes homolysis of the DPDS molecule, splitting it into two sulphenyl radicals, while various possible photodegradation effects were considered on a 'mock PMMA' chain that consists of two monomer units. These photodegradation effects were the removal of the $\mathrm{OCH}_{3}$ group from the side chain, removal of the $\mathrm{CH}_{3}$ group on the side chain, complete removal of the side chain and removal of the $\mathrm{CH}_{3}$ group from the main chain. These options were considered because damage to the side chains of PMMA is known to occur after UV exposure ${ }^{40,41}$. It was found that the attachment of the sulphenyl radical to the side chain after $\mathrm{OCH}_{3}$ removal is the most energetically favourable, followed by the attachment to the main chain after complete side chain removal, as shown by the change in free energies given in Table 1 . The other attachments to various parts of the PMMA molecule were also found to be more energetically favourable than recombining with another sulphenyl radical.

The photosensitivity of the POF and growth dynamics of the FBGs The mechanism that leads to photoinduced index changes in PMMA optical fibre under UV irradiation is complicated and still requires further investigation. The wavelength of $325 \mathrm{~nm}$ is used for the majority of the work ${ }^{42}$ on FBG inscription in POFs because PMMA starts to degrade upon UV irradiation below approximately $300 \mathrm{~nm}^{6}$, and $325 \mathrm{~nm}$ is one of the main emission lines of a HeCd laser. FBG formation in POFs continues for a long time (ranging from a few weeks to a few months) after the initial UV exposure.

The S-S bond of DPDS can be broken either by heat or under UV irradiation ${ }^{43-45}$ because it has a low bond dissociation energy $(214.2 \mathrm{~kJ}$ $\left.\mathrm{mol}^{-1}\right)^{46}$ compared with other core dopants such as diphenyl sulphide $\left(327.6 \mathrm{~kJ} \mathrm{~mol}^{-1}\right)$. Thermal homolysis occurs at $\sim 300^{\circ} \mathrm{C}^{47}$, which is higher than any temperatures achieved during fibre processing.

Under UV irradiation, homolysis of the DPDS occurs, and two sulphenyl radicals are created ${ }^{44}$. Disulphide bonds have been shown to break in $\sim 2 \mu \mathrm{s}$ after UV absorption in a protein system ${ }^{48}$. Therefore, with two phenyl groups attached by a disulphide bond, DPDS will undergo photodissociation on the order of microseconds, and the 
Table 1 Free energies of UV-induced reactions

\begin{tabular}{|c|c|c|c|c|}
\hline Reaction & Note & $\Delta G$ & $\Delta H$ & $\Delta E+Z \mathrm{PE}$ \\
\hline (a) & Recombination of sulphenyl radicals & -22.25 & -34.23 & -34 \\
\hline \multicolumn{5}{|l|}{$+(a) \rightarrow$ DPDS } \\
\hline$(a)+(b 1) \rightarrow(c 1)$ & $\mathrm{OCH}_{3}$ removed from side chain & -37.43 & -51.62 & -51.26 \\
\hline$(\mathrm{a})+(\mathrm{b} 2) \rightarrow(\mathrm{c} 2)$ & $\mathrm{CH}_{3}$ removed from side chain & -24.65 & -36.47 & -36.55 \\
\hline$+(\mathrm{b} 3) \rightarrow(\mathrm{c} 3)$ & Side chain removed & -30.43 & -46.08 & -45.34 \\
\hline$(a)+(b 4) \rightarrow(c 4)$ & $\mathrm{CH}_{3}$ removed from main chain & -23.34 & -37.07 & -36.90 \\
\hline
\end{tabular}

The relative energy values (in $\mathrm{kcal} \mathrm{mol}^{-1}$ ) of $\Delta G, \Delta H$ and $\Delta E+Z \mathrm{PE}$ calculated at the B3LYP/6$311++G(d, p)$ level of theory.

sulphenyl radicals can attach to photodegraded sites on the PMMA chain through the sulphur atom, which is supported by decreases in the Raman peaks associated with $\mathrm{S}-\mathrm{S}$ bonds $\left(407.1 \mathrm{~cm}^{-1}\right.$, $\left.529.8 \mathrm{~cm}^{-1}\right)$, C-S-S bonds $\left(695.9 \mathrm{~cm}^{-1}\right)$ and a slight increase in C-S bonds $\left(660.0 \mathrm{~cm}^{-1}\right)$ (Figure $6 \mathrm{~b}$ and $6 \mathrm{c}$ ). DPDS dissociation would also explain the slight increase in the C-S bond observed at $660.0 \mathrm{~cm}^{-1}$ after UV exposure (shown in Figure 6c) because breaking a DPDS molecule into two can potentially generate twice as many C-S bonds if the two parts of the molecule join onto a PMMA chain. The negligible change in the $\mathrm{v}(-\mathrm{S}-\mathrm{H})$ bond vibration seen at $2555 \mathrm{~cm}^{-1}$ (shown in Figure 6e) shows that the cleaved molecule rarely pairs up with any hydrogen radicals that might have been removed from the PMMA chain or elsewhere.

The stability of the phenyl rings ${ }^{49}$ means that the rings are relatively unharmed by the UV exposure ${ }^{50}$. The vibrational modes of the phenyl ring are observed to change because the DPDS molecule splits. Although some peaks are reduced, a few are strengthened after UV exposure, while others have split, broadened or developed shoulders. These changes suggest that the phenyl rings are mainly still intact but their attachments are now different. The peak splitting is especially indicative of there being several different possible configurations after the UV exposure. The development of the small shoulder at $991.3 \mathrm{~cm}^{-1}$ could also be due to full or partial scission of the side chain $^{51}$, although they would be difficult to isolate from changes in the phenyl signal at the same wavenumbers. The addition of aromatic rings and sulphur atoms is known to increase the refractive index of polymers $^{52}$.

Simulation results show that the most likely routes are the cleaving of the $\mathrm{OCH}_{3}$ from the side chain or total side chain scission, followed by replacement with the sulphenyl radical through the sulphur atom. This procedure agrees with the changes seen via Raman spectroscopy. These changes cause the rapid positive change in the refractive index achieved during the Bragg grating inscription when using DPDS as a dopant, which permits the grating to appear immediately after UV irradiation (Figure 2a). Shorter inscription times would be possible using a higher power $325 \mathrm{~nm}$ laser and a faster optical beam shutter.

When the UV fluence is low $\left(<65.8 \mathrm{~mJ} \mathrm{~cm}^{-2}\right)$, not many bonding sites are available on damaged PMMA chains (Norrish type I photochemical reaction ${ }^{53}$ ), and the final configuration is mostly uniform, giving well-defined reflection peaks in Figure 2a-2c. FBGs inscribed with higher UV energy fluences $\left(>65.8 \mathrm{~mJ} \mathrm{~cm}^{-2}\right)$ show evidence of the effect of Norrish type II photochemical reaction ${ }^{53,54}$, giving rise to more numerous final molecular configurations ${ }^{53}$, which creates irregularities along the irradiated regions of the fibre and thus the grating. This complexity is likely the cause of the higher noise seen in the FGBs written with longer exposure times, which is seen in Figure 2a-2c. The FBGs exhibited very good thermal stability (Figure 3), which is a well-established characteristic of vulcanization ${ }^{55}$. The exact cause of the growth of the reflected peak power of the gratings (Figure $2 \mathrm{~d}$ ) over several weeks requires further investigation, although these results suggest that further molecular rearrangement occurs over that time.

\section{CONCLUSIONS}

The discovery of DPDS as a single material for increasing both the refractive index of POFs and their photosensitivity is announced in this paper. This approach allows the rapid writing of FBGs. FBG inscription in just $7 \mathrm{~ms}$ is achieved, which is more than two orders of magnitude faster than the previously reported result of writing FBGs in POFs at the $325 \mathrm{~nm}$ wavelength. In this article, a demonstration of multiple vital signs monitoring using the $7 \mathrm{~ms}$ polymer FBG was conducted. The results show approximately 20 times improvement in the sensitivity for heartbeat measurements at the brachial artery location compared with silica-based FBG and at least 30 times improvement for both respiratory function and heartbeat monitoring at the chest location. An explanation of the photosensitivity, growth dynamics and thermal stability of FBGs inscribed in DPDS core-doped fibres is presented. These findings enable high-quality gratings in POFs to be produced during the fibre-drawing process-a significant step towards developing low-cost, single-use polymer fibre-sensing systems for biomedical applications. This result should also be of interest to the wider precision sensor industry, while further applications in Internet of Things and automation can also be envisioned.

\section{CONFLICT OF INTEREST}

The authors declare no conflict of interest.

\section{ACKNOWLEDGEMENTS}

This work was supported by the General Research Fund Project ( ${ }^{\circ}$ PolyU 152207/15E) and PolyU Central Grant project 1-ZVGB. JB acknowledges financial support from the Hong Kong Research Grants Council through the Hong Kong PhD Fellowship Scheme.

1 Liu HY, Liu HB, Peng G-D, Chu PL. Observation of type I and type II gratings behavior in polymer optical fiber. Opt Commun 2003; 220: 337-343.

2 Kalli K, Argyros A, Dobb H, Webb DJ, Large MCJ et al. Continuous wave ultraviolet lightinduced fiber Bragg gratings in few- and single-mode microstructured polymer optical fibers. Opt Lett 2005; 30: 3296-3298.

3 Bonefacino J, Cheng X, Tse M-LV, Tam H-Y. Recent progress in polymer optical fiber light sources and fiber bragg gratings. IEEE J Sel Top Quantum Electron 2017; 23: 252-262.

$4 \mathrm{Hu} \mathrm{XH}$, Kinet D, Mégret $\mathrm{P}$, Caucheteur $\mathrm{C}$. Control over photo-inscription and thermal annealing to obtain high-quality Bragg gratings in doped PMMA optical fibers. Opt Lett 2016; 41: 2930-2933.

5 Pospori A, Marques CAF, Bang O, Webb DJ, André P. Polymer optical fiber Bragg grating inscription with a single UV laser pulse. Opt Express 2017; 25: 9028-9038.

6 Alshehry SD, Ismail IMI. PMMA degradation protection investigation using ultraviolet additive. Orient J Chem 2008; 24: 35-42.

7 Yu JM, Tao XM, Tam HY. Fabrication of UV sensitive single-mode polymeric optical fiber. Opt Mater 2006; 28: 181-188.

8 Liu HB, Liu HY, Peng GD, Chu PL. Strain and temperature sensor using a combination of polymer and silica fibre Bragg gratings. Opt Commun 2003; 219: 139-142.

9 Xiong Z, Peng GD, Wu B, Chu PL. Highly tunable Bragg gratings in single-mode polymer optical fibers. IEEE Photonics Technol Lett 1999; 11: 352-354.

10 Lethien C, Loyez C, Vilcot J-P, Rolland N, Rolland PA. Exploit the bandwidth capacities of the perfluorinated graded index polymer optical fiber for multi-services distribution. Polymers 2011; 3: 1006-1028.

11 Fleming JW, Wood DL. Refractive index dispersion and related properties in fluorine doped silica. Appl Opt 1983; 22: 3102-3104.

12 Tam HY, Pun C-FJ, Zhou GY, Cheng X, Tse MLV. Special structured polymer fibers for sensing applications. Opt Fiber Technol 2010; 16: 357-366.

13 Roriz P, Frazão O, Lobo-Ribeiro AB, Santos JL, Simões JA. Review of fiber-optic pressure sensors for biomedical and biomechanical applications. J Biomed Opt 2013; 18: 50903.

14 Katsuragawa $\mathrm{Y}$, Ishizawa $\mathrm{H}$. Non-invasive blood pressure measurement by pulse wave analysis using FBG sensor. Instrumentation and Measurement Technology Conference 
(I2MTC); 11-14 May 2015; Pisa, Italy; 2015 IEEE International: doi: 10.1109/ I2MTC.2015.7151320.

15 Witt J, Krebber K, Demuth J, Šašek L. Fiber optic heart rate sensor for integration into personal protective equipment. International Workshop on BioPhotonics 2011; 8-10 June 2011; Parma, Italy; IEEE: doi: 10.1109/IWBP.2011.5954836.

16 Krehel M, Schmid M, Rossi R, Boesel LF, Bona G-L et al. An optical fibre-based sensor for respiratory monitoring. Sensors 2014; 14: 13088-13101.

17 Grillet A, Kinet D, Witt J, Schukar M, Krebber K et al. Optical fiber sensors embedded into medical textiles for healthcare monitoring. IEEE Sens J 2008; 8: $1215-1222$.

18 Kaye GWC, Laby TH. Tables of Physical and Chemical Constants16th edn.New York: Longman Scientific \& Technical. 1995.

19 NDC. Material Data Sheet Superelastic Nitinol Alloys 2012. https://confluentmedical. com/wp-content/uploads/2016/01/Material-Data-Sheet-Superelastic.pdf.

$20 \mathrm{He}$ XC, Handa J, Gehlbach P, Taylor R, Iordachita I. A submillimetric 3-DOF force sensing instrument with integrated fiber Bragg grating for retinal microsurgery. IEEE Trans Biomed Eng 2014; 61: 522-534.

21 Kiesel S, Peters K, Hassan T, Kowalsky M. Behaviour of intrinsic polymer optical fibre sensor for large-strain applications. Meas Sci Technol 2007; 18: 3144-3154.

22 Peng GD, Latif A, Chu PL, Chaplin RA. Polymeric guest-host system for nonlinear optical fibres. Nonlinear Optics: Materials, Fundamentals, and Applications, 1994. NLO '94 IEEE; 25-29 July 1994; Waikoloa, HI, USA; IEEE, 10.1109/ NLO.1994.470885.

23 Peng GD, Chu PL, Xiong ZJ, Whitbread TW, Chaplin RP. Dye-doped step-index polymer optical fiber for broadband optical amplification. J Light Technol 1996; 14: 2215-2223.

24 Webb DJ, Kalli K. Polymer fiber bragg gratings. In: Cusano A, Cutolo A, Albert J editors. Fiber Bragg Grating Sensors: Recent Advancements, Industrial Applications and Market Exploitation. Sharjah, UAE: Bentham Science Publishers. 2011, pp292-312.

25 Frisch MJ, Trucks GW, Schlegel HB, Scuseria GE, Robb MA et al. Gaussian 09, Revision D.01. Wallingford, CT, USA: Gaussian, Inc.. 2016.

26 Yu JM, Tao XM, Tam HY. Trans-4-stilbenemethanol-doped photosensitive polymer fibers and gratings. Opt Lett 2004; 29: 156-158.

27 Koike Y, Tanio N, Ohtsuka Y. Light scattering and heterogeneities in low-loss poly (methyl methacrylate) glasses. Macromolecules 1989; 22: 1367-1373.

28 Liu HY, Peng GD, Chu PL. Thermal tuning of polymer optical fiber Bragg gratings. IEEE Photonics Technol Lett 2001; 13: 824-826.

29 Jiang $\mathrm{CH}$, Kuzyk MG, Ding J-L, Johns WE, Welker DJ. Fabrication and mechanical behavior of dye-doped polymer optical fiber. J App/ Phys 2002; 92: 4-12.

30 Carroll KE, Zhang C, Webb DJ, Kalli K, Argyros A et al. Thermal response of Bragg gratings in PMMA microstructured optical fibers. Opt Express 2007; 15: 8844-8850.

31 Liu HB, Liu HY, Peng GD, Chu PL. Novel growth behaviors of fiber bragg gratings in polymer optical fiber under UV irradiation with low power. IEEE Photonics Technol Lett 2004; 16: 159-161.

32 Liu HY, Peng GD, Chu PL. Thermal stability of gratings in PMMA and CYTOP polymer fibers. Opt Commun 2002; 204: 151-156.

33 Yuan W, Stefani A, Bache M, Jacobsen T, Rose B et al. Improved thermal and strain performance of annealed polymer optical fiber Bragg gratings. Opt Commun 2011; 284: 176-182.

34 Kim C-S, Ober SL, McMurtry MS, Finegan BA, Inan OT et al. Ballistocardiogram: mechanism and potential for unobtrusive cardiovascular health monitoring. Sci Rep 2016; 6: 31297

35 Silva AF, Carmo JP, Mendes PM, Correia JH. Simultaneous cardiac and respiratory frequency measurement based on a single fiber Bragg grating sensor. Meas Sci Technol 2011; 22: 075801.

36 Xu XS, Ming H, Zhang QJI, Zhang YS. Properties of Raman spectra and laser-induced birefringence in polymethyl methacrylate optical fibres. J Opt A Pure Appl Opt 2002; 4: 237-242.
37 Szafranski CA, Tanner W, Laibinis PE, Garrell RL. Surface-enhanced Raman spectroscopy of aromatic thiols and disulfides on gold electrodes. Langmuir 1998; 14: 3570-3579.

38 Thomas KJ, Sheeba M, Nampoori VPN, Vallabhan CPG, Radhakrishnan P. Raman spectra of polymethyl methacrylate optical fibres excited by a $532 \mathrm{~nm}$ diode pumped solid state laser. J Opt A Pure Appl Opt 2008; 10: 055303.

39 Takata LMS, Gonçalves AC, Ando RA, Dos Santos AA, Camargo PHC. Functionalization of gold and silver nanoparticles with diphenyl dichalcogenides probed by surface enhanced Raman scattering. J Raman Spectrosc 2012; 43: 712-717.

40 Wochnowski C, Metev S, Sepold G. UV-laser-assisted modification of the optical properties of polymethylmethacrylate. Appl Surf Sci 2000; 154-155: 706-711.

41 Yu JM, Tao XM, Tam HY, Demokan MS. Modulation of refractive index and thickness of poly(methyl methacrylate) thin films with UV irradiation and heat treatment. App/ Surf Sci 2005; 252: 1283-1292.

42 Tomlinson WJ, Kaminow IP, Chandross EA, Fork RL, Silvast WT. Photoinduced refractive index increase in poly(methylmethacrylate) and its applications. App/ Phys Lett 1970; 16: 486-489.

43 Matxain JM, Asua JM, Ruipérez F. Design of new disulfide-based organic compounds for the improvement of self-healing materials. Phys Chem Chem Phys 2016; 18: 1758-1770.

44 Russell PG. Photoproduct formation in benzenethiol, diphenyl disulfide and disphenyl sulfide. J Phys Chem 1975; 79: 1353-1359.

45 Neves-Petersen MT, Gryczynski Z, Lakowicz J, Fojan P, Pedersen S et al. High probability of disrupting a disulphide bridge mediated by an endogenous excited tryptophan residue. Protein Sci 2002; 11: 588-600.

46 Luo Y-R. Comprehensive Handbook of Chemical Bond Energies. Boca Raton, Florida, USA: CRC Press. 2007.

47 Chandrasiri JA, Wilkie CA. Thermal degradation of diphenyl disulfide and a blend of diphenyl disulfide with poly(methyl methacrylate). Polym Degrad Stab 1994; 46: 275-284.

48 Abaskharon RM, Gai F. Direct measurement of the tryptophan-mediated photocleavage kinetics of a protein disulfide bond. Phys Chem Chem Phys 2016; 18: 9602-9607.

49 McMurray J. Organic Chemistry with Biological Applications2nd edn. Belmont, California, USA: Brooks/Cole Cengage Learning. 2011.

50 Yousif E, Haddad R. Photodegradation and photostabilization of polymers, especially polystyrene: review. Springerplus 2013; 2: 398.

51 Bensaid MO, Ghalouci L, Hiadsi S, Lakhdari F, Benharrats N et al. Molecular mechanics investigation of some acrylic polymers using SPASIBA force field. Vib Spectrosc 2014; 74: 20-32.

52 Higashihara T, Ueda M. Recent progress in high refractive index polymers. Macromolecules 2015; 48: 1915-1929.

53 Ivan MG, Scaiano JCTPhotoimaging and lithographic processes in polymersIn:Allen NSeditor. Photochemistry and Photophysics of Polymer Materials. Hoboken, New Jersey, USA: JohnWiley \& Sons, Inc. 2010, pp479-507.

54 Eve S, Mohr J. Study of the surface modification of the PMMA by UV-radiation. Procedia Eng 2009; 1: 237-240.

55 Johns J, Rao V. Thermal stability, morphology, and X-ray diffraction studies of dynamically vulcanized natural rubber/chitosan blends. J Mater Sci 2009; 44: 4087-4094.

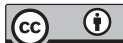

This work is licensed under a Creative Commons Attribution 4.0 International License. The images or other third party material in this article are included in the article's Creative Commons license, unless indicated otherwise in the credit line; if the material is not included under the Creative Commons license, users will need to obtain permission from the license holder to reproduce the material. To view a copy of this license, visit http://creativecommons.org/licenses/by/4.0/

(C) The Author(s) 2018

Supplementary Information for this article can be found on the Light: Science \& Applications' website (http://www.nature.com/lsa). 